\title{
SAKRAMEN BAPTIS SEBAGAI SAKRMEN KESELAMATAN DAN PERSEKUTUAN PARA MURID KRISTUS
}

\author{
Ola Rongan Wilhelmus \\ STKIP Widya Yuwana \\ olarongan@yahoo.com
}

\begin{abstract}
Baptism is a sacrament instituted and used by God Himself through Christ to purify, sanctify and to save human being out of the power of evil spirit. Baptism celebration maintaining in a proper and faithful manner will be brought about the fullness grace and favor of God to the Catholic faithful. The experiences of the Catholic faithful regarding God's grace and favor should not be only responded by full faith but also be properly responded by full action to bring it to the entire nations and human races. The Catholic Church as a communion of Christ disciples has been sent and guided by the Holy Spirit to spread out such grace and favor of God to all nations. Pastoral assembly of Surabaya Diocese conducted in 2019 strongly articulated that Baptism is a mean exactly used by God Himself to channel His grace and salvation to the entire human beings. Hence, the Disciples of Christ have to fully respond it by full faith and opened hart. Christ Himself has sent His disciples to collectively spread out the grace, favor and salvation of God to all over the world. This good news has to be brought firstly to the inner circle of the Catholic families, neighbours, communities, parishes, and diocese then to the society in general.
\end{abstract}

Keywords: Baptism, Grace, Salvation, Christ, Church, Disciples of Christ. 


\section{PENDAHULUAN}

Banyak tulisan membuat uraian secara partial tentang Sakramen Baptis. Terdapat tulisan-tulisan yang hanya menyoroti pembaptisan Yohanes Pembaptis, pembaptisan Paulus dan Pembaptisan dalam tradisi Gereja. Selain itu ada pula tulisan yang hanya menyoroti pembaptisan bayi dan anak, pembaptisan dewasa, wali baptis, dan lain-lain. Ada pula tulisan yang hanya mendiskusikan aspek teologis, biblis dan pastoral Sakramen Baptis. Hal ini mengakibatkan banyak pembaca memperoleh pengetahuan dan informasi partial dan kurang integratif tentang Sakramen Baptis. Melihat permasalahan ini maka tulisan ini mencoba mendiskusikan secara bersama beberapa aspek yang dirasa penting terkait Sakramen Baptis. Terlepas dari kekurangan yang masih ada, tulisan ini diharapkan dapat memberi informasi, masukan, serta gagasan biblis, teologis dan pastoral yang lebih integratif tentang Sakramen Baptis bagi para katekis, guru agama atau petugas pastoral lainnya yang diserahi tugas mendidik, mendampingi dan mendewasakan iman umat baik di Keuskupan, paroki, lingkungan ataupun stasi.

Tulisan ini dibuat dengan tujuan antara lain: Pertama, mendiskusikan sejumlah gagasan teologis, biblis dan bahkan historis tentang Sakramen Baptis sebagai sakramen keselamatan. Kedua, mendalami aspek praktis pastoral tertentu tentang Sakramen Baptis dalam hubungannya dengan Arah Dasar Pastoral Keuskupan Surabaya. Aspek pastoral yang lebih disoroti dalam tulisan ini ialah tugas perutusan para murid Kristus yang telah menerima Sakramen Baptis dan tanggung jawab orangtua serta wali baptis dalam pendidikan dan pendewasaan iman calon baptis. Menjawabi tujuan ini maka dalam tulisan ini akan mendiskusikan beberapa topik, antara lain: pembaptisan Yohanes Pembaptis; pembaptisan Paulus; pembaptisan dalam tradisi Gereja; pembaptisan bayi dan anak; serta wali baptis.

\section{PEMAHAMAN TENTANG BAPTIS}

Setiap ritus sakramen termasuk Sakramen Baptis dikenal dalam sejarah Gereja sebagai praktek. Gereja perdana sudah mengenal ritus-ritus tertentu yang dipandang penting dan mutlak dilakukan karena diimaninya sebagai salah satu bentuk pelaksanaan hidup dan tugas Gereja sebagai sarana keselamatan Allah bagi manusia. Ritus-ritus itu antara lain ritus pembabtisan. Sebagian besar unsur ritus pembaptisan diambil dari lingkungan sosial budaya dan agama lain. Meskipun demikian, arti, isi dan makna pembatisan ini telah diberi arti, isi dan makna baru dalam konteks iman Kristiani tentang rencana keselamatan Allah (Jebarus P. 2013: 10).

Ritus pembaptisan dalam Gereja Katolik berakar dalam kebiasaan dan adat-istiadat Yahudi. Agama Yahudi mengenal macam-macam upacara baptis 
(pembasuhan) untuk membersihkan diri dari dosa dan salah, sehingga layak mengambil bagian dalam suatu upacara keagamaan (Bdk. Im 15:5.8.10.13.18.22; Im 16:4.24). Ritus baptis Yahudi ini pada mulanya diambil alih Yohanes Pembaptis. Gereja Katolik kemudian mengambil alih ritus pembaptisan Yohanes Pembaptis. Pembaptisan Yohanes merupakan suatu gerakan "moral” dengan tujuan mendorong umat beriman Yahudi bertobat supaya terbebas dari murka dan hukuman Allah. Berbeda dengan tujuan pembaptisan Yohanes, tradisi Kristen Katolik melihat pembaptisan sebagai "Sakramen Keselamatan Allah”. Melalui Sakramen ini, Allah berinisiatif membersihkan dosa dan kesalahan umat beriman, mengangkatnya menjadi anak Allah serta menyatukannya dengan Gereja sebagai suatu persekutuan para murid Kristus (Jebarus P. 2013: 25).

Baptis berasal dari kata Yunani "baptizo" artinya "menenggelamkan sesuatu ke dalam air”. Kata baptizo juga memiliki beberapa arti lain yaitu: “mencelupkan”, “membasuh”, “mencuci”, dan “membersihkan”. Terkait arti kata ini, menarik ketika Injil Lukas 11:38 mengatakan: "Orang Farisi melihat hal itu dan ia heran karena Yesus tidak mencuci tangannya sebelum makan”. Kata "mencuci" dalam perikop ini pada tempat pertama mengandung arti mencuci tangan dengan cara cukup mencelupkan tangan ke dalam tempayan sekedar membasuh tangan sebelum makan. Jadi kata baptis mengandung arti membasuh, mencuci, dan membersihkan diri (tangan) dari noda atau kotoran yang melekat pada badan atau tangan seseoang ( Rudy, 2019: 5; Jebarus P. 2013: 3).

Rudy (2019) mengatakan praktek membersihkan atau membasuh tangan dengan air, tidak etis dan higienis jikalau seseorang mencelupkan tangannya yang kotor kedalam tempayan, sementara tempayan itu digunakan juga orang lain. Dengan demikian orang yang hendak membasuh tangan lazimnya mengambil gayung lalu menggayung air dari tempayan serta mengucurkannya ke tangan sendiri. Jadi penggunaan kata "baptizo" mengandung arti sangat fleksibel, dan tidak mutlak mengandung arti membenamkan seluruh diri ke dalam air. Ritus pembaptisan Gereja Pentekosta memutlakan pandangan bahwa pembaptisan itu dilakukan dengan cara membenamkan calon baptis ke dalam air. Pembaptisan tanpa membenamkan calon baptis ke dalam air merupakan "pembaptisan tidak sah”. Pandangan ini bertitik tolak dari Inji Matius 3:16: "Yesus segera keluar dari air”. Kata keluar dari air ditafsirkan mengandung arti seluruh tubuh Yesus sebelumnya dibenamkan kedalam air. Pada hal kata "keluar dari air" sesungguhnya tidak menunjukkan berapa banyak bagian tubuh Yesus sebelumnya dibenamkan dalam air. Banyak lukisan Kristen kuno tentang pembabtisan Yesus menunjukkan bahwa Yesus masuk ke air hanya sebatas lutut. Kesaksian Dokumen Gereja mengenai para rasul (200 M) mengatakan dalam liturgi pembaptisan jikalau air tidak cukup untuk membaptis maka pembaptisan bisa dilakukan cukup dengan cara pengucuran. Terkait praktek pembaptisan ini, Kitab Hukum Kanonik 
menegaskan bahwa pembaptisan bisa dilaksanakan dengan memasukan calon baptis dalam air atau dengan cara menuang atau pengucuran air, serta mengindahkan ketentuan-ketentuan yang berlaku (Kan. 854).

Kitab suci tidak memberikan petunjuk secara jelas tentang “cara” para Rasul membaptis: apakah dengan cara membenamkan seluruh tubuh ke dalam air atau cukup dengan dibasuh saja. Kesaksian Yustinus Martir mengatakan pembaptisan dilakukan dengan cara "masuk ke dalam air”. Banyak catatan sejarah Gereja menunjukan pembabtisan dilakukan dengan cara membenamkan seseorang ke dalam air. Cara ini lazim dilakukan oleh Gereja perdana. Meskipun demikian, cara ini telah berevolusi menjadi ritus pembaptisan lebih sederhana. Bagi Gereja Katolik, ritus pembaptisan apapun yang digunakan tetap tidak mengubah hakikat pembaptisan sebagai tanda keselamatan dan kelahiran baru karena iman akan Yesus Kristus (Rudy, 2019: 5; Jebarus, 2013: 27).

Praktek ritus pembaptisan dalam Gereja Katolik bersifat fleksibel karena disesuaikan dengan perkembangan pandangan teologis, perkembangan zaman dan juga konteks kehidupan setempat. Meskipun demikian, perubahan ritus pembaptisan tidak mengubah hakikat pembaptisan sebagai sarana Allah menyucikan, membersikan dan menyelamatkan manusia dari kekuatan dosa dan kuasa kegelapan. Pembaptisan menguduskan dan mengangkat manusia menjadi anak Allah dan mempersatukannya dengan Gereja sebagai suatu persekutuan para murid Kristus. Musyawarah Pastoral Keuskupan Surabaya dalam seri MUPAS Buku 1 (2019:7) sangat menekankan aspek keselamatan Sakramen Baptis. Melalui Sakramen ini, setiap murid Kristus diselamatkan, dikuduskan dan diangkat menjadi anak Allah, dibebaskan dari dosa, dan diterima sebagai anggota dari persekutuan para murid Kristus sebagai keluarga Allah. Rahmat pembaptisan ini juga memberi tugas perutusan (misioner) kepada setiap murid Kristus untuk mewartakan kabar sukacita tentang keselamatan dalam diri Yesus Kristus dan Injil kepada segala bangsa, serta membawa setiap orang dan komunitas manusia kepada Kristus sebagai dasar dan alasan keselamatan manusia. Pewartaan ini dimulai dari lingkungan terdekat yaitu keluarga, lingkungan dan stasi, paroki dan menyebar luas ke tengah masyarakat.

\section{PEMBAPTISAN SEBAGAI SAKRAMEN}

Sakramen merupakan tanda lahiriah keselamatan Allah yang ditetapkan Yesus Kristus dalam Gereja karena karya Roh Kudus. Tanda lahiriah ini mengungkapkan kebenaran adanya rahmat Allah yang diberikan kepada manusia dan manusia harus menerimanya dengan penuh iman demi keselamatannya. Thomas Aquinas memandang sakramen sebagai "bejana-bejana rahmat” (Vasa Gratiae), dan "bentuk kelihatan dari rahmat Allah tak yang kelihatan”. Jadi Allah menggunakan tanda-tanda kelihatan seperti air, minyak, hosti, anggur dan lain- 
lain untuk menyelamatkan manusia. Tanda-tanda keselamatan ini disebut causa instrumentalis yang digunakan Allah sendiri sebagai Causa Principalis demi keselamatan manusia. Jadi sakramen adalah sarana keselamatan Allah dimana Allah sendiri menjadi “sebab atau pelaku utama” keselamatan. Perbuatan Allah ini tidak bisa dihancurkan oleh siapa atau apa pun (Jebarus, 2013: 27).

Thomas Aquinas menjelaskan bahwa daya dan keabsahan sakramen tidak bergantung pada keadaan moral atau iman kepercayaan pemberi ataupun penerima sakramen, tetapi sepenuhnya bergantung pada kuasa Allah. Meskipun demikian, terdapat tuntutan minimal yang perlu dipenuhi manusia yang memberi ataupun yang menerima sakramen. Pemberi (pelayan) sakramen dituntut memiliki iman dan kehendak baik melakukan apa yang dikehendaki Gereja, sedangkan penerima dituntut beriman dan membuka diri terhadap rahmat keselamatan yang ditawarkan Allah kepadanya. Ia tidak boleh menutup diri atau acuh tak acuh. Pandangan Thomas Aquinas dipertegas Konsili Trente (1545-1563) dengan mengatakan bahwa keselamatan atau pembenaran Allah atas diri manusia terjadi karena rahmat Allah yang disalurkan melalui sakramen. Tapi keselamatan yang disalurkan melalui sakramen ini tidak mendatangkan keselamatan secara otomatis (ex opere operato), sebaliknya bergantung pula (sebagai syarat bukan penyebab) pada sikap hati (iman) penerima sakramen (Jebarus, 2013:9-10).

Terkait Sakramen Baptis, Kitab Hukum Kanonik (Kan. 849) mengartikan Sakramen Baptis sebagai pintu gerbang untuk sakramen-sakramen lainnya yang sangat dibutuhkan manusia untuk keselamatan. Melalui sakramen ini, setiap orang dibebaskan dari dosa, dilahirkan kembali sebagai anak-anak Allah, dipersatukan dengan Gereja sebagai persekutuan para murid Kristus dan menjadi serupa dengan Kristus. Konsili Trente menegaskan Sakramen Baptis merupakan salah satu Sakramen yang dicetak Allah dalam jiwa manusia sehingga tidak binasa karena kekuatan dosa dan kejahatan sekalipun.

Katekismus Gereja Katolik (KGK, 1992) mengartikan Sakramen Baptis sebagai Sakramen Kristus, Sakramen Gereja, Sakramen Iman, Sakramen Keselamatan dan Sakramen kehidupan kekal. Disebut Sakramen Kristus sebab Sakramen ini ditetapkan Yesus Kristus sendiri melalui perkataan ataupun perbuatanNya yang menyelamatkan. Disebut Sakramen Gereja karena tindakan keselamatan Kristus atas diri manusia terjadi melalui Gereja berkat karya Roh Kudus. Setiap orang hanya bisa menerima sakramen ini melalui Gereja. Sakramen ini dapat bekerja secara sah dan efektif kalau upacara penerimaan sakramen ini dilaksanakan secara baik dan benar. Sakramen Baptis disebut juga sebagai Sakramen Iman sebab sakramen ini dapat menumbuhkan, menguatkan, serta mendewasakan iman seseorang akan Yesus Kristus. Iman itu diungkapkan antara lain melalui doa sehingga doa pada hakikatnya merupakan bagian dari ungkapan iman. Tentang hubungan antara doa dan iman ini, pepatah Latin mengatakan: 
“lex orandi, lex credendi”, artinya hukum doa adalah hukum iman. Umat beriman percaya kepada Yesus sebagaimana ia berdoa kepadaNya. Sakramen Baptis disebut Sakramen Keselamatan sebab sakramen ini merupakan sarana yang dipakai Allah untuk keselamatan manusia. Perayaan sakramen secara pantas dengan penuh iman akan menyalurkan rahmat keselamatan bagi manusia. Terakhir, Sakramen Baptis merupakan Sakramen Hidup Kekal karena memberi jaminan akan kehidupan kekal kepada manusia (Bdk. KGK. 1236; 818; 846).

Tindakan keselamatan Allah melalui Sakramen Baptis hendaknya diimani, diwartakan, dan diamalkan Gereja. Gereja sebagai persekutuan murid Kristus diberi tugas mewartakan kepada manusia dan dunia tentang jalan hidup, kebenaran dan keselamatan Allah bagi manusia melalui Yesus Kristus dan Injil. Konsili Vatikan II menyebut Gereja sebagai persekutuan iman, harapan dan cinta para murid Kristus yang menerima Kristus dengan penuh iman dan cinta kasih (bdk. LG. 8; GS. 32). Gereja ini diutus Kristus menghimpun dan mempersatukan semua orang dari berbagai suku dan bangsa supaya beriman kepadaNya sebagai jaminan keselamatan. Gereja yang dibentuk oleh unsur Ilahi (Roh Kudus) dan unsur manusiawi (umat beriman) dituntut terlibat aktif (actuosa participtio) dalam karya pewartaan Injil dan Yesus Kristus (KWI. 1996:392).

Seri MUPAS Buku ke-4 (2019: 29) Keuskupan Surabaya menegaskan bahwa Sakaramen Baptis sebagai Sakramen keselamatan telah mempersatukan setiap umat beriman Katolik dalam suatu persekutuan yaitu Gereja yang terdiri dari para murid Kristus yang dikepalai Kristus. Persekutuan para murid Kristus ini secara konkret tinggal dalam suatu wilayah paroki yang terbentuk dari berbagai lingkungan dan stasi. Sebagai suatu persekutuan, umat beriman Katolik hendaknya saling menyemangati, menguatkan, memberi perlindungan serta saling membantu dalam menumbuh-kembangkan imannya akan Yesus Kristus dan Injil agar iman itu semakin berkembang dan dewasa. Persekutuan para murid Kristus yang dewasa dalam iman tercermin dari perjumpaan dan dukungan intensif antara warga lingkungan dan paroki dalam hal pendidikan dan pendewasaan iman. Iman yang dewasa diharapkan dapat membentuk Gereja Keuskupan Surabaya sebagai suatu “organisme hidup” yang memiliki karakter: penuh iman, penuh pelayanan, guyup, dan misioner.

\section{PEMBAPTISAN YOHANES PEMBAPTIS}

Agama Yahudi dan agama-agama asli sekitar lingkungan Yahudi sudah lama mengenal upacara pembasuhan atau pembersihan. Pada masa hidup Yesus, umat Yahudi telah mengenal upacara pembaptisan mengenang kasih, kebaikan dan keselamatan Allah yang dialami bangsa Yahudi saat melintasi laut merah. Dalam kerangka upacara pembaptisan umat Yahudi ini, muncul gerakan moral pembaptisan Yohanes Pembaptis sebagai “tanda pertobatan” (Mat 3:11). 
Bab pertama Injil Lukas menceritakan bagaimana Yohanes Pembaptis tampil di padang gurun sambil menyerukan pertobatan agar terbebas dari murka Allah. Seruan ini didengarkan banyak orang dan mereka pun bertobat lalu datang ke sungai Yordan untuk dibaptis (Mrk. 1:4-5). Stefan Leks (2002: 107; 111) mengatakan bahwa baptisan Yohanes merupakan persiapan dan solusi moral bagi orang Israel saat menghadapi “murka Allah yang akan datang”, Yohanes sadar bahwa Allah segera menghukum bangsa Israel kalau tidak bertobat. Satu-satunya solusi supaya bebas dari murka dan hukuman Allah ialah bertobat.

Uraian tentang pembaptisan Yohanes menempatkan pembaptisan dalam konteks pertobatan karena takut akan murka dan hukuman Allah. Setiap orang yang bertindak bertentangan dengan kehendak Allah dan merusak hubungan dengan Allah dan sesama hendaknya bertobat, menyucikan diri dan berpaling kepada Allah sumber kasih, kebaikan dan keselamatan. Sabda Tuhan: "bertobatlah dan berilah dirimu dibaptis dan Allah akan mengampuni dosamu" (Mrk 1:4). Maka "sambil mengaku dosanya mereka dibaptis Yohanes Pembaptis di sungai Yordan” (Mat 3:6). Dalam Gereja Katolik, pertobatan diungkapkan melalui sikap sesal dan tobat serta membersihkan diri dari dosa melalui Sakramen Tobat sebagai sarana pengampunan Allah atas dosa manusia.

Penginjil Markus menceritakan Yesus juga datang kepada Yohanes untuk dibaptis (Mrk.1:9-11). Ketika keluar dari air, Ia melihat surga terbuka dan Roh Kudus dalam rupa seekor burung merpati turun ke atasNya. Kemudian terdengar suara yang mengatakan: "Engkaulah PutraKu yang terkasih; kepadamu aku berkenan” (Mrk 1:11). Segera setelah peristiwa pembaptisan di Sungai Yordan, Yesus dibawa Roh Allah ke padang gurun dan tinggal di sana untuk berdoa dan berpuasa selama 40 hari sebagai persiapan mewartakan Kerajaan Allah di tengah masyarakat (Mrk. 1:12-13). Selama menjalani masa doa dan puasa, Yesus mendapat godaan luar biasa dari iblis, namun godaan itu dipatahkanNya karena kekuatan doa dan puasa. Bagian akhir Injil Markus mencatat kata-kata terakhir Yesus yang dialamatkan kepada para Rasul: "Pergilah ke seluruh bumi dan wartakanlah Injil... Barangsiapa percaya dan dibaptis akan diselamatkan” (Mrk 16:15) (Bdk. Rudy T. 2019).

Setelah pembaptisan, para murid Kristus diutus mewartakan Yesus Kristus dan InjilNya sebagai jalan hidup, kebenaran dan keselamatan Allah bagi manusia. Pewartaan ini dilakukan baik dengan kata-kata maupun dengan kesaksian hidup nyata tentang pengalaman akan kasih dan kebaikan Allah. Dalam pewartaan, murid Kristus tentunya mengalami banyak cobaan iblis atau kekuatan jahat yang ingin membuatnya jatuh ke dalam dosa sebagaimana Yesus alami di pandang gurun. Seri MUPAS Buku 1 (2019: 13) mengingatkan para murid Kristus bahwa dalam peziarahan di dunia, para murid Kristus tidak jarang berhadapan dengan kekuatan jahat yang berusahan membuatnya jatuh ke dalam dosa. Dosa itu 
mengotori bahkan memutuskan kemesraan relasi Allah dan manusia. Terputusnya relasi ini membuat murid Kristus gagal menghasilkan buah-buah kebaikan. Hal ini terungkap jelas dalam Sabda Yesus: “Akulah pokok anggur dan kamulah rantingrantingnya. Barangsiapa tinggal di dalam Aku dan Aku di dalam dia, ia berbuah banyak, sebab di luar Aku kamu tidak dapat berbuat apa-apa” (Yoh.15:5). Kutipan ini mengungkapkan bahwa syarat bagi murid Kristus supaya tidak jatuh dalam dosa dan berbuah banyak ialah tetap menyatu dengan pokok anggur yaitu Yesus Kristus.

Ritus pembaptisan Yohanes diambil alih Gereja perdana. Injil Yohanes Yoh 3:22.26 menceritakan Yesus pergi ke tanah Yudea dan membaptis. Meskipun demikian, Yesus sendiri sebenarnya tidak pernah melakukan kegiatan membaptis kecuali para muridNya (Yoh 4:2), namum Yesus memberi perintah kepada para muridNya untuk membaptis (Mat 28:19; Mrk 16:16). Merespon perintah Yesus, Petrus berseru kepada orang banyak: "Bertobatlah dan hendaklah kamu masingmasing memberi dirimu dibaptis dalam nama Yesus Kristus demi pengampunan dosamu dan mendapatkan karunia Roh Kudus” (Kis 2:38).

Bila direnungkan pembaptisan Yohanes dan pembaptisan Petrus (Gereja perdana) maka terlihat adanya kemiripan mencolok diantara keduanya, walaupun tetap ada perbedaan tajam. Perbedaan itu terlihat dari dua kalimat pendek yang diucapkan Petrus dalam seruan tentang pertobatan dan pembaptisan yaitu: "dalam nama Yesus Kristus” dan “kamu akan menerima karunia Roh Kudus”. Tambahan kedua kalimat pendek ini mengungkapkan bahwa seruan pertobatan dan pembaptisan para murid Yesus tidak hanya mengandung arti pertobatan karena takut akan murka dan hukuman Allah, melainkan tobat karena "iman akan Yesus Kristus”. Pembaptisan atas nama Yesus tidak hanya membawa pengampunan dosa dan keselamatan tetapi juga "karunia Roh Kudus" yang memberi kesaksian bahwa setiap orang yang beriman dan dibaptis atas nama Yesus merupakan anakanak Allah yang dikasihi Allah (Rm 8:16).

Yesuslah yang memberi perintah kepada para muridNya melakukan pembaptisan. Oleh karena itu pembaptisan yang dilakukan para murid bukan atas nama mereka sendiri melainkan Yesus Kristus. Yesuslah yang memberi kuasa kepada para murid untuk membaptis. Kuasa ini mengakibatkan setiap orang yang dibaptis harus beriman pada Yesus, menjadi serupa dengan Yesus, mengalami pengampunan dosa, diselamatkan dan siap memberi kesaksian tentang Yesus Kristus dan Injil. Kesaksian ini akan efektif, memberdayakan iman akan Yesus, dan menghasilkan buah-buah kebaikan bila dibimbingan Roh Kudus. Seri MUPAS Buku 1 (2019: 24-25) mengatakan bahwa proses pendewasaan iman para murid Kristus membutuhkan bantuan dan bimbingan Roh Kudus. Bimbingan ini membuat para murid Kristus semakin dewasa dalam iman, lebih berani dan sanggup mewartakan perbuatan-perbuatan keselamatan yang dilakukan Allah 
(Kis 2:11), menjadi garam dan terang dunia (Mat 5:13-16), dan siap sedia berbagi karunia rohani kepada sesama yang dijumpai. Ciri murid Kristus yang dewasa dalam iman ialah tertib beribadat, rajin menjalankan kegiatan devosional, tekun mempelajari dan mendalami kebenaran iman, rajin membaca dan menghayati Kitab Suci dan Ajaran Gereja, dan siap sedia diutus mewartakan kabar sukacita tentang Yesus Kristus dan Injil di tengah masyarakat.

\section{PEMBAPTISAN PAULUS}

Rasul St. Paulus berpendapat bahwa inti Sakramen Baptis ialah “mengambil bagian dalam wafat dan kebangkitan Kristus”. Hal ini terungkap dalam Roma 6:4 yang mengatakan bahwa "Kita telah dikuburkan bersama-sama dengan Dia oleh baptisan dalam kematian supaya sama seperti Kristus telah dibangkitkan dari antara orang mati oleh kemuliaan Bapa, demikian juga kita akan hidup dalam hidup yang baru”. Menyusul Gal 3: 27 mengatakan: "Yang dibaptis dalam Kristus, telah mengenakan Kristus”. Kedua perikop ini mengungkapkan pemahaman Paulus tentang pembaptisan sebagai sarana pemersatu umat beriman dengan Kristus. Surat kepada Kolose 2:12 menjelaskan: "Bersama Kristus kamu dikuburkan dalam pembaptisan, dan di dalam Dia kamu turut dibangkitkan oleh kepercayaanmu kepada kuasa Allah yang membangkitkan Dia dari orang mati”. Dalam kutipan ini Paulus menekankan pembaptisan sebagai inisiasi Kristen. Dalam surat kepada Titus, Paulus mengembangkan konsep pembaptisan sebagai sarana keselamatan yang diberikan Allah kepada manusia secara cuma-cuma berkat karya Roh Kudus. Sabda Tuhan: "Karena rahmatNya oleh pembaptisan yang merupakan kelahiran kembali karena pembaruan yang dikerjakan Roh Kudus” (Tit 3:5) (Bdk. Rudy T. 2019; Alex J. 2016).

Dalam 1 Kor 12:13, Rasul St. Paulus mengemukakan lagi satu konsep baru dalam kaitannya dengan "anggota tubuh Kristus atau Gereja”. "Dalam satu Roh kita semua dibaptis menjadi satu tubuh dan kita semua diberi minum dari satu Roh”. Melalui pembaptisan, setiap orang terbaptis menerima karunia Roh Kudus menjadi anggota tubuh Kristus yaitu Gereja. Disini terungkap sifat "inisiasi” pembaptisan sebagai sarana pemersatu umat beriman dengan Kristus dalam suatu persekutuan yaitu Gereja. Dalam persekutuan ini, "tidak ada lagi orang Yahudi atau orang Yunani, tidak ada lagi hamba atau orang merdeka, tidak ada lagi laki-laki atau perempuan karena kamu semua adalah satu dalam Kristus Yesus” (Gal 3:28). Pembabtian dalam nama Kristus menghapus semua perbedaan dan pertentangan suku dan kelas karena semua orang terbaptis telah menjadi satu anggota tubuh Kristus (Bdk. Rudy T. 2019; Alex J. 2016).

Bagi Paulus, pembaptisan merupakan sarana persekutuan umat beriman dengan Kristus. Persekutuan ini mendatangkan hidup baru dan menyebabkan seseorang menjadi anggota tubuh Kristus yaitu Gereja. Persekutuan ini 
menghilangkan semua perbedaan suku, budaya, ras dan jenis kelamin sebab semua murid Kristus telah menjadi satu dalam diri Kristus sendiri. Perbedaan dan pertentangan suku, budaya dan ras sudah hilang dan lebur (Bdk. Gal 3:28). Seri MUPAS Buku 4 (2019: 5) Keuskupan Surabaya menjelaskan bahwa sejak awal mula, Yesus Kristus sendiri sebagai Guru telah memanggil para murid, memilih dan menyatukan mereka dengan dirinya sendiri serta membentuk suatu persekutuan yang disebut Gereja (Bdk. Mat 10: 1-4; Mark 3: 13-19). Persekutuan dengan Kristus dan Gereja ini terjadi ketika seseorang menerima Sakramen Baptis. Persekutuan ini dibentuk dengan tujuan agar Sang Guru Ilahi yaitu Kristus sebagai kepala persekutuan ini dapat mengutus muridnya menyampaikan kabar sukacita tentang Yesus Kristus dan Injil kepada segala bangsa (Bdk. Mat 10: 5-15; 6: 6b-12). Tugas perutusan ini bukan dilakukan secara individu melainkan kolektif. Tidak dapat disangkal bahwa kondisi para murid Kristus pada umumnya sangat variatif karena terdiri atas berbagai macam orang dari latar belakang kelompok, suku, bahasa, golongan dan status sosial berbeda. Meskipun demikian, perbedaan ini tidak perlu menjadi alasan mengendorkan semangat kebersamaan dan saling mendukung dalam menjalankan tugas perutusan Yesus di tengah masyarakat.

\section{PEMBAPTISAN DALAM TRADISI GEREJA}

Yohanes Pembaptis membaptis dengan air dan para murid Yesus juga melakukan pembaptisan dengan cara yang sama. Tempat pembaptisan biasanya di sekitar sungai atau kolam air. Pembaptisan dilakukan dengan cara membenamkan calon baptis ke dalam kolam. Upacara pembaptisan ini sangat menekankan aspek pengakuan iman akan Allah Tritunggal. Pengakuan iman Trinitaris ini mengakibatkan Gereja Katolik kemudian mengembangkan kebiasaan menanyakan calon baptis beberapa pertanyaan Trinitaris saat pembaptisan: Percayakah saudara akan Allah Bapa yang Mahakuasa, pencipta langit dan bumi?; Percayakah saudara akan Yesus Kristus, Putra-Nya yang tunggal, Tuhan kita?; Percayakah saudara akan Roh Kudus, Gereja Katolik yang kudus, persekutuan para kudus, pengampunan dosa, kebangkitan badan dan kehidupan kekal?. Setiap pertanyaan ini harus dijawab calon baptis atau wali baptis dengan mengatakan: "Ya, saya percaya” sebelum calon baptis dibaptis (Bdk. Alex J. 2016).

Buku "Inisiasi Kristen" saat ini menetapkan bahwa pemimpin upacara baptis perlu mengajak calon baptis mengungkapkan imannya dengan menjawab tiga pertanyaan Trinitaris. Hal ini bisa terlihat dari tiga pertanyaan Trinitaris yang ditanyakan kepada calon baptis saat sebelum pembaptisan. Seri MUPAS Buku 1 (2019: 16) Keuskupan Surabaya menegaskan bahwa kesediaan seseorang untuk menerima pembaptisan hendaknya ditunjukan dengan pengakuan iman akan Yesus Kristus yang sengsara, wafat, dan bangkit dari antara orang mati. Setiap 
orang yang percaya kepada Yesus dibebaskan dari dosa, dilahirkan kembali sebagai putra-putri Allah, dan disatukan dengan Gereja berkat karya Roh Kudus (Bdk. Kan. 849). Jadi pembaptisan mengakibatkan seseorang memiliki ikatan Ilahi dengan Tritunggal Maha Kudus karena dibaptis dalam nama Bapa, dan Putra dan Roh Kudus sebagaimana diperintahkan Yesus sendiri.

Konsili Vatikan II dalam Dokumen Sacrosanctum Concilium (SC.6) mengatakan: "Melalui pembaptisan, seseorang dimasukkan ke dalam misteri Kristus: Ia mati, dikuburkan dan dibangkitkan bersama Dia; Ia menerima Roh dan diangkat menjadi anak, dan dalam Roh itu berseru: Abba, Bapa. Dokumen Lumen Gentium (LG.11) mengatakan: "Dengan pembaptisan kaum beriman dimasukan ke dalam persekutuan dengan Gereja”. Jadi Sakramen Baptis merupakan bagian dari rencana keselamatan Allah bagi manusia (Bdk. LG. 5-6). Dalam kaitan dengan keunikan persekutuan murid Krsistus (Gereja) yang dibentuk Yesus Kristus atas karya Roh Kudus ini, Konsili Vatikan II menolak pandangan bahwa semua persekutuan itu sama, sebab persekutuan murid Kristus terbentuk oleh faktor iman akan Yesus Kristus dan karya Roh Kudus. Inilah yang membedakan persekutuan para murid Kristus dari persekutuan lain.

Berdasarkan keunikan persekutuan murid Kristus itu, maka Gereja terus mendorong anggotaNya supaya tetap semangat dan setia menjalankan tugas perutusan mewartakan Yesus Kristus dan Injil sebagai jalan kebenaran dan hidup bagi semua bangsa. Gereja mendorong agar tetap fokus mengumpulkan, mempersatukan dan menjalankan semua bangsa murid Yesus serta membaptis mereka atas nama Bapa, Putra dan Roh Kudus. Sabda Tuhan: "Karena itu pergilah, jadikanlah semua bangsa murid-Ku dan baptislah mereka dalam nama Bapa dan Anak dan Roh Kudus, dan ajarlah mereka melakukan segala sesuatu yang telah Kuperintahkan kepadamu. Dan ketahuilah, Aku menyertai kamu senantiasa sampai kepada akhir zaman". (Mat 28: 19-20). Seri MUPAS Buku 1, (2019: 16) menegaskan bahwa hal yang membedakan persekutuan murid Kristus dari persekutuan atau komunitas lain ialah iman kepada Yesus Kristus dan karya Roh Kudus. Yesus sendiri menjadi dasar, pusat dan pendiri persekutuan murid Yesus. Melalui persekutuan ini murid Yesus mendapatkan daya Ilahi yaitu Roh Kudus yang menguduskan dan menyelamatkan persekutuan ini (Bdk. LG 4), dan mengutusnya untuk menyumbangkan kasih karunia-karunia Roh Kudus yang diterima dari Allah untuk pembangunan dan keselamatan semua orang.

\section{PEMBAPTISAN ANAK}

Kitab Suci tidak menceritakan secara eksplisit tentang pembaptisan anak dan bayi. Kis 16:33 memang menceritakan bahwa kepala penjara Filipi "memberi diri dibaptis, ia dan keluarganya”. Kutipan ini tidak mengungkapkan secara eksplit terjadinya pembaptisan bayi dan anak. Pada zaman St. Agustinus 
(354-430), pembaptisan anak dan bayi sudah menjadi kebiasaan umum, terutama di Afrika. Orang dewasa jarang dibaptis ketika itu. Kebiasaan membaptis bayi dan anak ini dipengaruhi oleh pandangan teologis mengenai dosa asal yaitu jikalau bayi dan anak tidak dibaptis maka mereka akan masuk naraka setelah meninggal, sebab dosa asal yang melekat pada mereka belum mendapatkan pengampunan Allah. Pandangan ini mengakibatkan pembaptisan bayi dan anak menjadi sangat populer saat itu. Pandangan teologis ini juga mendorong Gereja menawarkan ritus pembaptisan darurat dan pendek untuk bayi dan anak yang sedang berada dalam bahaya kematian (Katoliksitas. 2019).

Pada awal abad XI, sejumlah uskup mengingatkan kemungkinan besar bahwa bayi dan anak-anak selalu dalam bahaya kematian tiba-tiba. Karena alasan ini maka orangtua didorong supaya segera membaptis anak mereka pada mingguminggu pertama setelah kelahiran, dan tidak menunggu hingga malam paskah. Akibatnya, kebiasaan melakukan pembaptisan hanya pada malam paskah mulai hilang. Upacara pembaptisan juga boleh hanya disaksikan anggota keluarga inti saja. Pada tahun 1950-an, para ahli sejarah Gereja melakukan studi mengenai ritus-ritus pembaptisan abad pertama. Berdasarkan hasil studi itu maka direvisi dan diterbitkan sebuah ritus pembaptisan anak-anak tahun 1969. Ritus pembaptisan ini menekankan kembali aspek komunal perayaan Sakramen Baptis. Dianjurkan supaya perayaan sakramen ini dilaksanakan dalam rangka perayaan Ekaristi yang dihadiri banyak orang. Ritus ini juga menganjurkan agar orangtua terlebih dahulu menjalani masa pendidikan dan pembinaan iman sebelum anak dibaptis. Konsep teologis tentang ritus ini bergeser dari konsep lama mengenai pembaptisan sebagai "jaminan masuk surga” kepada konsep baru yaitu pembaptisan sebagai “inisiasi Kristen”. Konsep baru ini mengutamakan aspek kesatuan (komunio) umat beriman dengan Kristus karena pembaptisan. Tahun 1980, sebuah Dokumen Gereja Katolik kembali menegaskan bahwa jika orangtua tidak bisa memastikan anaknya dididik dan dibesarkan seturut iman Katolik maka pembaptisan anak dapat ditunda sampai tidak ada batas waktu tetentu (Katoliksitas. 2019; Katoliksitas. 2012).

Sejak abad permulaan hingga pertengahan, pembaptisan anak dilakukan atas dasar konsep teologis tentang jaminan masuk surga. Pertimbangan keselamatan jiwa ini mengakibatkan praktek pembaptisan mengabaikan aspek komunal dan tanggung jawab orangtua dalam pendidikan dan pendewasaan iman anak. Akan tetapi sejak pertengahan abad XX, ritus pembaptisan kembali menekankan aspek komunal dengan menempatkan upacara pembaptisan dalam rangka perayaan Ekaristi bersama umat beriman. Sakramen baptis lebih dilihat sebagai inisiasi Kristen dalam rangka menerima baptisan baru dalam persekutuan dengan Gereja. Supaya lebih banyak umat beriman hadir dalam pembaptisan, maka dianjurkan pembaptisan dilakukan pada hari Minggu. Demikian pula 
diupayakan agar pembaptisan anak dilakukan pada minggu-minggu pertama setelah kelahiran anak. Kitab Hukum Kanonik mengatakan meskipun pembaptisan dapat dilakukan pada hari apa saja, tetapi dianjurkan agar dilakukan pada hari Minggu atau malam Paskah (Bdk. Kan. 856 \& 867).

Ritus pembaptisan saat ini menekankan pula tanggung jawab orangtua atas pendidikan dan pendewasaan iman anak. Orangtua perlu memastikan bahwa anaknya dididik dan dibesarkan seturut iman Katolik. Buku liturgi pembaptisan anak saat ini memberikan alasan bahwa anak-anak dibaptis karena iman orangtua. Mereka dibaptis sebagai anak yang masih bergantung penuh pada orangtua dalam segala hal termasuk iman. Pembaptisan anak mendapat arti penuh dalam iman dan tanggung jawab orangtua bersama umat beriman. Atas dasar alasan ini maka dalam upacara pembaptisan, orangtua ditanya pemimpin upacara: "maukah saudara supaya anak ini dipersatukan dengan Yesus Kristus dan diterima sebagai anggota umat Allah?”. Jadi orangtua berkewajiban memberi teladan kepada anak dalam hal kehidupan iman (Katoliksitas, 2019; Katoliksitas, 2012).

Terkait peran orangtua dalam pendidikan dan pendewasaan iman anak, Seri MUPAS Buku 4 (2019:7-8) menegaskan bahwa kehidupan Gereja dibentuk pertama-tama oleh keluarga yang terdiri dari orangtua dan anak. Keluarga merupakan komunitas pertama yang dibentuk orangtua melalui perjumpaan suami-isteri yang percaya kepada Kristus dan saling mencintai. Iman dan cinta kasih suami-isteri ini disatukan dalam Sakramen Perkawinan. Keluarga yang dibentuk atas dasar iman akan Kristus ini disebut "Ecclesia Domestica" (Gereja Kecil). Sebagai Ecclesia Domestica, orangtua bertanggungjawab penuh membangun kehidupan rumah tangga dan mendidik anak-anak yang Tuhan percayakan kepada mereka dalam terang iman, kasih dan harapan Yesus. Orangtua bertanggungjawab melaksanakan misi Gereja dalam keluarga yaitu mewartakan kabar sukacita tentang Yesus dan Injil kepada kepada keluarga khususnya anak-anak. Orangtua diutus menjadi terang dan garam dalam keluarga dengan menghadirkan, meresapi dan mewariskan kepada anak-anak nilai-nilai Injil dan iman akan Yesus Kristus.

\section{WALI BAPTIS}

Wali baptis sangat dibutuhkan dalam upacara pembaptisan. Hal ini disebabkan Gereja memerlukan kesaksian umat beriman sebagai jaminan bahwa calon baptis layak dibaptis atas dasar iman akan Yesus Kristus. Wali baptis bertanggungjawab membuktikan kepada pimpinan Gereja bahwa calon baptis itu seorang yang baik dan pantas dibaptis. Kesaksian ini diberikan setelah mengenal, bekerja dan berdoa bersama keluarga dan calon baptis dalam kurun waktu tertentu. Jadi wali baptis dituntut terlibat aktif membina dan mendampingi iman calon baptis terutama selama calon baptis menjalankan masa katekumenat ataupun 
setelah pembaptisan. Masa persiapan ini berlangsung kurang lebih 3 tahun atau disesuaikan dengan kebijakan lokal. Sementara itu, masa persiapan akhir paling kurang selama satu bulan menjelang pembaptisan. Kegiatan masa persiapan akhir mencakup doa rutin, pantang dan puasa, serta meneliti kelayakan calon baptis. Setelah itu calon baptis diantar ke hadapan uskup atau imam untuk dibaptis. Pada saat itu wali baptis harus memberi jaminan bahwa calon baptis layak dibaptis dan tidak memiliki tabiat buruk (Handoko P.2017; Rudy T. 2019).

Wali baptis dibutuhkan dalam upacara pembaptisan untuk memberi kesaksian secara benar tentang kelayakan calon baptis. Kitab Hukum Kanonik (Kan 872) mengaskan bahwa Calon baptis sedapat mungkin diberi wali baptis untuk mendampinginya dalam upacara pembaptisan. Wali baptis bersama orang tua calon baptis secara bersama mengajukan calon baptis untuk dibaptis. Wali baptis bertanggungjawab dalam pendidikan dan pendewasaan iman calon baptis agar kelak setelah baptis dapat menjalankan hidup sesuai iman Kristiani serta setia memenuhi kewajiban-kewajiban yang melekat pada dirinya sebagai orang terbaptis. Kan 874 secara khusus menegaskan bahwa wali baptis hendaknya memiliki kemampuan dan keterampilan menjalani tugas sebagai wali baptis. Oleh karena itu, wali baptis hendaknya seorang dewasa berusia sekurang-kurangnya genap 16 tahun, beriman Katolik, sudah menerima sakramen Krisma dan Ekaristi, dan sudah terbukti menjalankan hidup seturut iman Katolik.

Wali baptis merupakan wakil umat lingkungan, stasi dan paroki. Keterlibatan wali baptis dalam persiapan calon baptis mengungkapkan bahwa pendidikan dan pendewasaan iman calon baptis merupakan tanggung jawab kolektif para murid Kristus. Seri MUSPAS Buku 4 (2019:6) Keuskupan Surabaya menjelaskan bahwa persekutuan para murid Kristus yang dewasa dalam iman senantiasa menghadirkan perjumpaan dan dukungan antara warga lingkungan dan paroki dalam hal pendewasaan iman. Perjumpaan dan dukungan ini akan membentuk Gereja sebagai suatu “organisme hidup” yang memiliki karakter unik yaitu penuh iman dan pelayanan, guyup, dan misioner. Persekutuan semacam ini hanya dapat ditampilkan secara konkret melalui keluarga dan lingkungan yang menjalani keseharian hidup dalam semangat Keluarga Kudus Nasaret. Keluarga dan lingkungan sebagai basis persekutuan murid Kristus dipanggil untuk mengupayakan cara hidup sebagaimana diajarkan Yesus: "haruslah kamu sempurna, sama seperti Bapamu di surga sempurna adanya” (Mat 5:48).

Organisme hidup warga lingkungan dan paroki sangat bergantung pada kualitas kehidupan keluarga. Paroki dan lingkungan yang baik berasal dari keluarga yang baik. Hal ini telah disadari sepenuhnya oleh Musyawarah Pastoral Keuskupan Surabaya. Seri MUPAS Buku ke 4 (2019: 7-8) menegaskan bahwa paroki dan lingkungan yang terlibat aktif di tengah masyarakat menuntut pendampingan yang baik bagi keluarga, sebab keluarga merupakan formasi 
pertama lingkungan yang perlu mendapatkan perhatian khusus. Dalam keluarga itu berbagai generasi dengan keunikannya masing-masing bertemu dan saling membantu untuk meraih kesempurnaan hidup sebagaimana dikehendaki Yesus. Keluarga merupakan dasar bagi kehidupan sosial-kemasyarakatan (Bdk. GS 52). Oleh karena itu, perangkat paroki dan lingkungan hendaknya memberikan perhatian serius kepada keluarga. Sangat penting bagi umat lingkungan memberi perhatian ketika keluarga mengalami persoalan, kesulitan ekonomi, berduka dan lan-lain.

\section{PENUTUP}

Sakramen Baptis merupakan Sakramen keselamatan. Pembaptisan mendatangkan hidup baru karena pembaptisan mempersatukan umat beriman dengan Kristus. Kesatuan ini merupakan unsur terpenting karena melalui kesatuan ini seseorang dilahirkan secara baru dalam Kristus dan berhak mendapatkan keselamatan Allah. Upacara pembaptisan Katolik selalu ditempatkan dalam kerangka inisiasi iman karena melalui pembaptisan seseorang menyatakan imannya secara penuh kepada Yesus Kristus dan Injil sebagai jalan kebenaran, hidup dan keselamatan. Iman ini harus diwartakan para murid Kristus yang telah menerima pembaptisan.

Ritus pembaptisan Katolik saat ini sangat menekankan unsur dan tanggung jawab kolektif. Oleh karena itu upacara pembaptisan selalu ditempatkan dalam kerangka Perayaan Ekaristi Kudus bersama umat beriman. Tanggung jawab kolektif ini juga terlihat dari tanggung jawab umat beriman dalam diri wali baptis mendidik dan mendewasakan iman calon baptis, terutama baik selama menjalani masa katakumenat maupun setelah pembaptisan.

Tanggung jawab kolektif terlihat juga dari penegasan Gereja bahwa orangtua harus memastikan anaknya dididik dan dibesarkan sesuai iman Katolik sebelum pembaptisan. Gereja menekankan pentingnya tanggung jawab orangtua atas pendidikan dan pendampingan iman anak mengingat anak dibaptis karena iman orangtua dan masih bergantung penuh kepada orangtua. Orangtua hendaknya menjadi suri teladan bagi anak dalam hal membaca dan menghayati nilai-nilai Injil dan iman akan Yesus Kristus. 


\section{DAFTAR PUSTAKA}

Gaudium et Spes (GS), 1965, Pastoral Constitution in the Modern World.

Handoko Petrus, 2017, Wali Baptis, Masihkah Diperlukan?. Hidup Katolik. https://www.hidupkatolik.com/2017/09/14/12875/wali-baptis-masihkahdiperlukan.

Jebadu Alex, 2016, Sakramen Baptis dan Sejarah Perubahan Ritus. Iman Katolik: Media Informasi dan Sarana Katekese. http://www.imankatolik.or.id.

Jebarus Pino, 2013, Bahan Kuliah Sakramentologi. STKIP St. Paulus Ruteng. KWI, 1985, Kitab Hukum Kanonik (KHK). Edisi Resmi Bahasa Indonesia.

KWI, 1996, Konferensi Wali Gereja Indonesia. Iman Katolik-Buku Informasi dan Referensi, Yogyakarta: Kanisius.

KWI, 2007, Katekismus Gereja Katolik (KGK).

Katoliksitas, 2012, Sakramen Gereja Katolik. htttp://katolisitasindonesia.blogspot.com/2012/07/dasar-sakramen-gereja-katolik.html.

Katoliksitas, 2019, Sakramen: Apa pentingnya di dalam kehidupan iman kita?. http://www.katolisitas.org/sakramen-apa-pentingnya-di-dalam-kehidupaniman-kita/.

Lumen Gentium (LG), 1962, Dogmatic Constitution On the Church. Art. 4 \& 11

Rudy Thomas, 2019, Baptisan dan Hidup Baru. Iman Katolik: Media Informasi dan Sarana Katekese. http://www.imankatolik.or.id.

--------------, 2019, Baptis Bayi. Iman Katolik: Media Informasi dan Sarana Katekese. http://www.imankatolik.or.id.

Sacrosanctum Concilium (SC), 1963, Constitution on the Sacred Liturgy. Art.6

Seri MUSPAS, 2019, Buku 1. Arah Dasar Keuskupan Surabaya Tahun 20202030. Surabaya Tahun 2020-2030.

Stefan Leks, 2002, Tafsiran Injil Lukas, Yogyakarta: Kanisius. 